March 4, 1998

\title{
Alternative Dispute Resolution
}

\section{Robert H. Mnookin}

Alternative dispute resolution (ADR) refers to a set of practices and techniques aimed at permitting the resolution of legal disputes outside the courts. It is normally thought to encompass mediation, arbitration, and a variety of "hybrid" processes by which a neutral facilitates the resolution of legal disputes without formal adjudication. These alternatives to adjudication are advocated on a variety of grounds. Potential benefits are said to include the reduction of the transaction costs of dispute resolution because ADR processes may be cheaper and faster than ordinary judicial proceedings; the creation of resolutions that are better suited to the parties' underlying interests and needs; and improved ex post compliance with the terms of the resolution.

The focus of this article is on mediation and arbitration and not on unfacilitated negotiation which is, of course, the most common means by which parties and their counsel resolve legal disputes outside of court. Part I provides essential background for understanding ADR by focusing on arbitration and mediation. By comparing these processes with adjudication and negotiation - the two procedures conventionally used to resolve legal disputes - the potential advantages and disadvantages of arbitration and mediation are exposed and briefly analyzed. Next, in Part II, a variety of hybrid processes often included within the scope of ADR are briefly described. These hybrids suggest that ADR procedures are now frequently included as processes within a dispute resolution system that includes formal adjudication. Part III briefly summarizes the theoretical scholarship that seeks to explore the incentive effects created by adding a layer of ADR to the litigation process, and also describes those few empirical studies that have explored its impact.

\section{Understanding Arbitration and Mediation}

Proponents of ADR regularly argue that arbitration and mediation - the two primary ADR processes - reduce the transaction cost of resolution and otherwise lead to better outcomes. In assessing the benefits and costs of these procedures it is, of course, necessary to ask: Compared to what? Normally, arbitration is compared with conventional litigation (“adjudication”); mediation with unfacilitated negotiation. The proponents' claims are best understood by comparing adjudication, arbitration, negotiation and mediation along a number of common dimensions: whether participation is voluntary or involuntary; the nature of the proceeding and the degree of its procedural formality; the role, if any, of a 
third party or neutral; the extent to which the outcome is binding; whether the outcome must be reached by application of legal norms; and whether the process is public or private (Goldberg et al. 1992) (pp. 4-6).

\section{Adjudication and Arbitration}

Adjudication is an involuntary process, in the sense that a court has the power (once its jurisdiction is properly invoked by a plaintiff) to coerce a defendant into either participating in the process or suffering the consequences of a default judgment. The judge, a neutral third-party appointed by the state, has the power and responsibility to run the proceedings and to resolve the dispute. The judicial proceedings are highly structured, with formal rules governing pre-trial discovery and the trial itself - i.e. what counts as evidence, the order in which evidence is presented and how arguments are made. In reaching its decision, the adjudicator is responsible for making a principled and reasoned decision based on legal norms. The trial judge's decisions are binding on the parties, subject to appeal to a higher court. Finally, adjudication is a public process - the judge is a public official, and the proceedings themselves are ordinarily open to the public and not confidential.

Like adjudication, arbitration also involves a neutral third party (the arbitrator) who is responsible for running the process and making the decisions necessary to resolve the dispute. Unlike a judge (a public official) the arbitrator is typically a private person chosen by the parties. The person chosen to arbitrate the dispute often has specialized expertise in the subject matter of the dispute; legal training is required only if the parties so specify. A dispute that might otherwise go to court becomes subject to binding arbitration only by the agreement of the parties. In this sense, arbitration is a creature of contract, and the terms of the parties' particular arbitration agreement are generally controlling. Before any dispute has arisen, parties often contract to arbitrate future disputes; arbitration provisions are frequently included in commercial contracts for the sale of goods and services, in labor agreements (Ashenfelter and Bloom 1984) and in joint ventures agreements. An agreement to arbitrate can also be made after a dispute has arisen, as the result of a negotiation between parties already in conflict. Binding arbitration in lieu of judicial adjudication is voluntary in the sense that it is only by agreement that one is required to arbitrate; but once there is an agreement it is involuntary in the sense that courts will enforce it against a reluctant party by refusing to adjudicate disputes which are within the scope of the arbitration agreement and thus require arbitration.

In an arbitration proceeding, the procedural rules may be set by the parties in their arbitration agreement. Pretrial discovery is typically limited or eliminated, and each party is given an opportunity to present proofs and arguments at a hearing where the procedures are typically much less formal than those found in court. Depending upon the parties' agreement, the arbitrator may or may not be asked to render a principled decision supported by a reasoned opinion. Often the arbitrator is free simply to announce the award without any explanation. In "final-offer" arbitration, by agreement of the parties the arbitrator is required to resolve the dispute by choosing one or the other of the "final-offers" submitted by the disputants - the arbitrator lacks all power to impose any other result (Farber 1980). (This is sometimes called "baseball arbitration" in the United States because it is used to resolve salary disputes in major league 
baseball.) In all of these examples, however, the decision of the arbitrator is characteristically binding and final, and subject to judicial review only if a party can show that the arbitrator was corrupt or acting outside the scope of the jurisdiction conferred by the parties' agreement.

Compared to court-based adjudication, the potential advantages and disadvantages of arbitration flow from three fundamental differences. The first has to do with the fact that parties can choose the arbitrator, whereas a judge is typically assigned. An arbitrator can be chosen with expertise in the subject matter of the dispute, whereas a judge is typically a generalist who is knowledgeable about legal procedures but may have no relevant experience and background relevant to the dispute. This can mean, for example, that a maritime dispute over damaged goods can be arbitrated by a person who is knowledgeable about the conventional practices in that industry; or that a software dispute concerning the adequacy of customdeveloped software can be resolved by someone who is familiar with the technology. As a consequence less hearing time may be required to "educate" an expert arbitrator than a generalist judge. In comparison to a judge, an arbitrator's decision may also be better informed and more predictable. As a result, arbitration may have both lower transaction costs and higher quality results than conventional adjudication.

A second set of potential advantages relates to the fact that an arbitration may proceed more quickly because of its comparative procedural informality. In conventional litigation, the costs of pre-trial discovery - taking pretrial depositions and answering interrogatories - can be very time-consuming and make up a very high proportion of the total transaction costs. Because arbitration typically either severely limits or eliminates pre-trial discovery, these costs can be eliminated. This is not, of course, an unmitigated advantage, for it may imply that a disputant will never discover favorable factual information in the hands of the other party, and may be surprised by unfavorable information that is first disclosed at the hearing.

The third critical difference relates to the scope of judicial review. Unlike rulings of a trial court which are subject to appellate review for mistakes of law or findings of fact that are unsupported by the evidence, an arbitrator's award cannot be overturned by an appellate court for these sorts of errors. The binding nature and comparative finality of an arbitrator's award is, of course, a mixed blessing. On the one hand, a final resolution may be more prompt and appeals infrequent because the scope of review is so narrow. On the other hand, a losing party lacks the safeguard of ordinary judicial review, which may improve the "accuracy" of the resolution.

\section{Negotiation and Mediation}

Unlike adjudication or arbitration, negotiation does not require the participation of a neutral thirdparty with decisional authority. Instead, the parties themselves have the responsibility for deciding the terms of any resolution. Negotiation is voluntary, in the sense that disputing parties are not ordinarily forced to negotiate with each other. The process of negotiation is informal and without defined procedures or rules governing the presentation of evidence or arguments. Because the goal of negotiation is a mutually acceptable resolution, the parties to a negotiation can shape that resolution to suit their own needs and interests, and are under no obligation to reach a principled outcome, much less one justified by a reasoned 
opinion applying formal legal norms. If resolution is reached, the settlement is not ordinarily subject to judicial review. The settlement agreement can subsequently be enforced as a contract. Negotiation is typically private; the process itself is not open to the public.

Like adjudication and arbitration, mediation also involves the use of a third-party, but a mediator unlike an arbitrator or judge has no authority to impose a resolution on the parties. Instead, the mediator's goal is to facilitate negotiation and help the parties themselves to reach a mutually acceptable settlement of their own dispute. Mediation is typically a voluntary process where the parties themselves may choose the person who will act as the outside facilitator. It is private and confidential, and not open to the public.

Although the mediator is typically responsible for managing the mediation process, there are no standard procedures or fixed rules. The process by which the mediator facilitates negotiation is often informal and unstructured. The actual practices of individual mediators vary greatly. While most mediators spend at least some time working with the parties together, practices vary concerning the use of "caucuses". Many but not all mediators also meet privately and separately with each side in a "caucus", often with an explicit ground-rule that the mediator will not share what is learned with the other side. Among other things, this is thought to encourage each party to share confidential information with the mediator. Although such ex parte contact would ordinarily be considered improper for a judge or arbitrator, mediators commonly use such caucuses to explore various settlement possibilities.

The practices of mediators vary along other dimension as well. For example, some mediators encourage the participation of lawyers, while others aim to minimize their participation to keep the spotlight on the parties themselves. Some mediators focus the process primarily on the strengths and weaknesses of each party's legal positions; others, primarily on the underlying interests and needs of the parties, trying to avoid discussion of the legal merits. Some mediators evaluate the legal merits of each party's positions, and willingly express a view of the probable outcome in court. Other mediators avoid evaluation, and instead see their role as facilitation, trying to help the parties generate creative options that serve underlying interests. Many mediators are eclectic, and engage in activities that both help the parties to understand the opportunities and risks of pursuing their litigation and also probe their underlying interests to see if there are value-creating options that may be quite unrelated to what a court might do.

A mediated resolution may on the one hand simply reflect the net expected value of what is likely to happen in court or, on the other, can be shaped to meet the needs and interests of the parties by making trades that are unrelated to the legal disputes. So long as the resulting resolution is mutually acceptable to the parties, there is no need that it involve the application of formal legal norms or mimic the outcome which a court might impose. There is typically no process of review. If parties are able to resolve their dispute by reaching a mediated agreement, that agreement is subsequently enforceable as a contract.

What are the advantages of mediation? Proponents argue that a skilled mediator can often help parties reach a negotiated outcome when they would be unable to do so on their own. They also suggest that even if the parties might be able eventually to settle on their own, a mediator may help parties reach 
better agreements with lower transaction costs - in other words, the mediated agreement may often be Pareto-superior to the one the parties might have reached on their own.

In considering the potential benefits of mediation, it is helpful to consider critical underlying theoretical questions: What are the reasons that negotiations fail? What are the barriers to the efficient resolution of conflict by negotiation? In this regard, scholars employing a variety of disciplinary perspectives have identified various barriers to Pareto-efficient negotiations (Arrow et al. 1995). By identifying these barriers, one can than explore how a neutral third-party mediator might help parties to overcome them (Mnookin 1993).

The conventional law and economics theory of settlement suggest that parties may fail to settle because they have divergent expectations about what will happen at trial (Landes 1971, Gould 1973). With sufficiently convergent expectations about the outcome in court, the theory suggests that disputants will settle the case in a way that divides the transaction cost savings that flow from avoiding further litigation. The obvious question is whether mediators can eliminate or reduce divergent expectations in circumstances where the parties themselves are either unable to do so themselves or can only do so with much greater transaction costs. If a mediator is able to produce more convergent expectations faster or at a lower cost, the neutral can thereby help overcome a barrier to dispute resolution (Arrow et al. 1995). As a theoretical proposition, this might be possible for a variety of reasons. A neutral may facilitate the exchange of essential information and improve communications between the parties, thus improving the parties' understanding of each other's claims and defenses. Moreover, to the extent that partisan perceptions are leading one or both parties to assessments which are overly optimistic (Arrow et al. 1995), a respected neutral may be able to overcome this bias. Shavell (1995) has questioned why two rational disputants would not do this on their own, especially in anticipation of a pretrial discovery process in which most everything may come out anyway. While this may be true with strong rationality assumptions and particular types of theoretical bargaining models, this argument does not take into account either irrational behavior or the ways that strategic interaction might sometimes inhibit the exchange of information essential for expectations to converge.

Adverse selection and moral hazard represent such strategic barriers. Brown and Ayres (1994) have argued that mediators can mitigate these problems and create value in negotiations between rational actors through sequential caucusing, by controlling and manipulating the information flows between the parties. They identify three ways a mediator can accomplish this: (1) by ending negotiations where there are no gains to be made from trade; (2) by committing parties to dividing the gains from trade equally; and (3) by committing to send noisy translations of information disclosed during private caucuses.

Ayres and Nalebuff (1997) argue that common knowledge can also act as a barrier to efficient negotiation. They suggest circumstances where the parties wish to communicate first order information (both parties know Fact $\mathrm{X}$ ) but avoid communicating higher-order information (A knows that B knows X; A knows that $\mathrm{B}$ knows that $\mathrm{A}$ knows that $\mathrm{B}$ knows $\mathrm{X}$ ) or creating common knowledge. They give examples where first order information would in fact facilitate dispute resolution but where higher order knowledge 
would cause negotiations to unravel. Mediators, according to Ayres and Nalebuff, can break the link between communicating first order information and higher-order information, thus promoting efficiency.

In addition to these game-theoretically based possibilities, there may be other ways in which mediators can dampen the risk posed by strategic interaction. With respect to the distributive aspects of bargaining, one or both parties may employ a variety of "hard bargaining tactics", in the hope of forcing the other side to pay more or accept less. And yet such negotiation tactics may drive out the possibility of exchanging information that would permit value to be created and the pie expanded (Lax and Sebenius 1986). To the extent that a mediator is able to encourage the parties to engage in collaborative problem solving and to dampen strategic interaction, transaction costs may be reduced and the parties may also be able to discover ways to create value and expand the pie.

Principal-agent problems can also act as a barrier to settlement that a mediator may help overcome. A lawyer may want to continue a dispute in order to increase his fees; or a manager, whose conduct gave rise to a dispute, may seek vindication in circumstances where it would serve the interest of the corporation to settle. A neutral may be able to facilitate settlement by getting the right people to the table and helping them understand their underlying interests (Mnookin 1993).

That there are a variety of ways that mediators might efficiently promote more Pareto-effective negotiation outcomes does not, of course, prove that they in fact do so with sufficient frequency to justify the involuntary imposition of mediation (Shavell 1995). But it does suggest how theoretical insights related to negotiation can inform the exploration of mediation.

\section{Hybrid Processes.}

While the arbitration and mediation procedures described above provide basic alternatives to formal adjudication, ADR also encompasses a variety of "hybrid" dispute resolution processes that use neutrals in ways that represent variations on the basic alternatives. Some of these hybrid processes are binding. For example, some states have statutes authorizing "private judging", which is a form of binding arbitration but one where the decision-maker is often a retired judge or private lawyer who is required to make a principled decision, sometimes supported by findings of fact and conclusions of law, which are binding on the parties but subject to appeal.

Other hybrid procedures are mandated by state law but are non-binding. In some jurisdictions, for example, before a party can have a judge resolve a dispute the case is first subject to "court-annexed mediation", an involuntary, confidential process where a mediator attempts to facilitate a negotiated resolution. Other states, require litigants to participate in "early neutral evaluation", a form of courtannexed mediation where a neutral helps the parties to arrange for efficient discovery and also provides an early, impartial report evaluating the strengths and weaknesses of each disputant's claims and defenses. In other jurisdictions, disputes involving comparatively small amounts are subject to "court-annexed arbitration", which is typically involuntary, non-binding, and public. The arbitrator's decision is made 
public, and often serves as the basis of settlement, but is not binding upon the parties - either party has a right to a de novo trial before a judge.

A "MiniTrial" is a form of mediation in which the parties select a neutral "advisor", who orchestrates for the benefit of an executive from each disputant an abbreviated formal hearing where the lawyers from each side present the core legal arguments and evidence that will be presented in court. Thereafter, the advisor works with these executives to see if a resolution can be negotiated. A "Summary Jury Trial" involves a non-binding process in which a mock-jury is impanelled by the court, and each party has an opportunity to present its case in abbreviated form. After the mock-jury renders its advisory verdict, the neutral attempts to facilitate (as a mediator) a negotiated resolution (Posner 1986). A "Neutral Expert" is typically a third party with special subject matter expertise who may either be selected by the parties voluntarily or by a Court under the Federal Rules of Evidence. Typically, the expert is asked to conduct an investigation and then write a report that may contain findings of fact. While usually not binding on the parties, the report may sometimes be the focal point for a negotiated settlement, and if not, is sometimes admissible in court.

\section{Incentive Effects of ADR Within Dispute Settlement Systems}

Several of the hybrid examples suggest that a dispute resolution system often involves the possibility of linking several different procedures. When parties negotiate concerning the resolution of a legal dispute (whether or not assisted by a mediator) they typically do so "in the shadow" of some other process - such as adjudication or arbitration - that can ultimately impose a resolution (Mnookin and Kornauser 1979). Various forms of mediation and arbitration are now sometimes embedded into the formal system of adjudication. Whether by agreement of the parties or by the imposition of law, procedures are often sequenced - parties may first negotiate on their own; and then be obligated to mediate before having a case adjudicated or arbitrated. In other words, various procedures can be used in conjunction with each other.

This suggests an important question for law and economics: What incentive effects are created when some form of ADR is added to the litigation process? In considering the desirability of ADR these effects must be considered, both theoretically and empirically, for adding a layer of ADR can have important and complex effects both on the frequency with which suits are brought and on the settlement process. Posner considers these issues in his examination of the Summary Jury Trial (Posner 1986) and Shavell provides a more comprehensive economic model for their consideration (Shavell 1995).

Using the standard model of litigation, Shavell explores the incentive effects of adding ADR to the litigation process. He contrasts ex ante ADR, where parties voluntarily agree to ADR before a dispute has arisen, with ex post resort to ADR after a dispute has arisen. For Shavell, the key question is whether or not ADR leads to changes in pre-dispute behavior that raises joint value for the parties. Shavell suggests that $e x$ ante agreements made by knowledgeable parties increase the expected utility of the parties and raise social welfare. He argues that ex ante agreements should ordinarily be enforced because of the potential 
advantages of ADR, and the "frequent inability" to negotiate them after the dispute arises. Because ex post ADR does not have incentive effects on the parties' pre-trial behavior, after analyzing the effects on the litigation process using the "standard model" of litigation Shavell suggests that there is "no apparent basis" for the state to impose involuntary ex post "non-binding" ADR. While it is possible that ex post ADR may be a cheap substitute for a trial, Shavell correctly points out that ADR may increase the frequency of suits and encourage people to engage in ADR who otherwise would have settled. And in the worst case, ADR might perversely simply add another layer to the litigation process without promoting settlement. As Shavell acknowledges, his analysis omits the possibility that ADR may promote efficient resolution of disputes by (a) altering the parties' opinions of trial outcomes through the exchange of information or consultation with the neutral; or (b) dampening client-lawyer agency problems.

Some empirical work has been done relevant to policy debates concerning the wisdom of mandating ADR within the civil justice system. A history of the development of court-administered arbitration programs, and an evaluation of the research concerning its effects may be found in (Hensler 1986; 1992). For Federal Courts in the United States, the Civil Justice Reform Act of 1990 established pilot programs in six districts that used various modes of ADR, including court-annexed mediation and early neutral evaluation, in order to reduce costs and delay. The institute of Civil Justice of the RAND Corporation has evaluated these programs, and found that neither time to disposition nor costs were changed in a statistically significant way (Kakalik et al. 1996).

\section{Conclusion}

When parties need to resolve a legal dispute, a trial before a state-sanctioned court is only one alternative - and one infrequently chosen at that. Most civil suits are in fact resolved by negotiation not by adjudication - by "bargaining in the shadow of the law". Arbitration, mediation and a variety of hybrid procedures now represent an array of other possible ways in which a third party (other than a judge) can be involved in dispute resolution. Whether and how ADR helps to overcome barriers to achieving Paretoefficient outcomes, and the effects of its introduction on incentives to settle and the efficiency of the dispute resolution system, warrant further theoretical and empirical study by law and economics scholars. 


\section{$\underline{\text { References }}$}

Arrow, K.; Mnookin, Robert ;Ross, Lee; Tversky, Amos \& Wilson, Robert, Ed. (1994). Barriers to Conflict Resolution.

Ashenfelter, O., Bloom, David E. (1984). "Models of Arbitrator Behavior: Theory and Evidence." American Economic Review 74: 111-124.

Ayres, I. Nalebuff, Barry J. (1997). “Common Knowledge as a Barrier to Negotiation.” UCLA

Law Review.

Brown, J. , Ayres Ian (1994). “Economic Rationales for Mediation.” Virginia Law Review 80: 323-401.

Farber, H. S. (1980). “An Analysis of Final-Offer Arbitration.” Journal of Conflict Resolution 24: 683-705.

Goldberg, S. B. , Sander, Frank E.A. \& Rogers, Nancy (1992). Dispute Resolution: Negotiation, Mediation and Other Processes (2nd edition).

Gould, J. P. (1973). “The Economics of Legal Conflict.” Journal of Legal Studies 2: 279-xx.

Hensler, D. R. (1986). “What We Know and Don't Know About Court-Administered Arbitration.” Judicature(February-March 1986): ??-??

Hensler, D. R. (1992). Court-Ordered Arbitration: An Alternate View. Santa Monica, CA., Institute of Civil Justice.

Kakalik, J. S. et. al (1996). An Evaluation of Mediation and Early Neutral Evaluation under the Civil Justice Reform Act. Santa Monica CA, Institute of Civil Justice, The RAND Corporation.

Landes, W. M. (1971). “An Economic Analysis of the Courts.” Journal of Law and Economics 14: 61-xx.

Lax, D. A., Sebenius James K. (1986). The Manager As Negotiator.

Mnookin, R. H. (1993). "Why Negotiations Fail: An Exploration of Barriers to the Resolution of Conflict." Ohio State Journal on Dispute Resolution 8(2): 235-249.

Mnookin, R. H., Kornhauser, Lewis (1979). "Bargaining in the Shadow of the Law: The Case of Divorce." Yale Law Journal ??: ??-?? 
Posner, R. A. (1986). “The Summary Jury Trial and Other Methods of Alternative Dispute Resolution: Some Cautionary Observations." University of Chicago Law Review 53: 366-393.

Shavell, S. (1995). “Alternative Dispute Resolution: An Economic Analysis.” Journal of Legal Studies 24(January): 1-28. 